\title{
Análise histológica do trato gastrintestinal de avestruzes jovens (Struthio camelus Linnaeus, 1758)
}

\author{
Cristina Maria Rodrigues Monteiro* \\ Nair Trevisan Machado de Souza \\ Roberto Gameiro de Carvalho \\ Wilson Machado de Souza \\ Faculdade de Odontologia de Araçatuba, Universidade Estadual Paulista \\ Departamento de Apoio, Produção e Saúde Animal \\ Rua Clóvis Pestana, 793 \\ CEP 16050-680, Araçatuba - SP, Brasil \\ *Autor para correspondência \\ monteiro@fmva.unesp.br
}

Submetido em 29/10/2008

Aceito em 16/03/2009

\section{Resumo}

Aspectos histológicos do trato gastrintestinal do avestruz (Struthio camelus) são pouco estudados, portanto, é de interesse desta pesquisa ampliar tais estudos. Para isso foram obtidas amostras de diferentes segmentos do tubo digestório de cinco avestruzes jovens, com idade entre 20 a 30 dias. Com base nos resultados obtidos pudemos concluir que os diferentes segmentos do tubo digestório do avestruz jovem apresenta a mesma estrutura geral de outras aves e mamíferos domésticos, com pequenas diferenças, como ausência de inglúvio e vesícula biliar, intestino grosso maior que o intestino delgado e ceco com propriedades fisiológicas semelhantes ao estômago de ruminantes. Estas variações são inerentes à espécie ou podem ser decorrentes da idade e hábito alimentar. Esperamos que esta análise contribua para uma melhor compreensão dos processos fisiológicos relacionados à nutrição e ao manejo do avestruz durante seu crescimento.

Unitermos: avestruz, histologia, trato gastrintestinal

\section{Abstract}

Histological analysis of the gastrointestinal tracts of young ostriches (Struthio camelus). The histological aspects of the gastrointestinal tract of the ostrich (Struthio camelus) have been little studied, so this research is focused on such analysis. To this end, samples were obtained from different segments of the digestive tubes of five young ostriches aged 20 to 30 days. Based on the results, the authors conclude that the different segments of the digestive tube of the young ostrich presents the same general structure as that of other domestic birds and mammals, with some differences that may be due to age, the species involved, or feeding habits. It is hopes that this analysis will contribute to a better understanding of the physiological processes related to the nutrition and management of ostriches during their growth.

Key words: gastrointestinal tract, histology, ostrich 


\section{Introdução}

O avestruz (Struthio camelus) é uma ave pertencente ao grupo das Ratitas (o esterno apresenta o formato achatado), ordem Struthioniforme, família Struthionidae, oriunda da savana africana, herbívora, apresenta diferenças morfológicas em relação a outras aves e semelhanças com os ruminantes (bovinos, ovinos e caprinos). No final da década de 60 , a África do Sul já dispunha de um importante plantel, capaz de fomentar e trazer novos rumos à estrutiocultura mundial (Santa Marta Avestruz, 2006).

Ao chegar ao Brasil em meados dos anos 90, o avestruz tornou-se uma opção bastante atrativa para a agropecuária brasileira devido ao seu grande potencial zootécnico, sobretudo na produção de carne, couro, ovos, plumas e matrizes. Atualmente, a região de Araçatuba é responsável pela comercialização e fornecimento de matrizes e demais produtos de avestruz para outras regiões (Marinho et al., 2004).

Pesquisas vêm sendo desenvolvidas em diversas áreas, como atestam os trabalhos de Bezuidenhout (1986) e de Iji et al. (2003), em anatomia e fisiologia, respectivamente. Devido à escassez de investigações quanto aos aspectos histológicos do trato gastrintestinal, objetivou-se nesta pesquisa realizar um estudo mais detalhado da morfologia dos diferentes segmentos do tubo digestório.

\section{Material e Métodos}

Utilizaram-se amostras do trato gastrintestinal de cinco filhotes de avestruz, de ambos os sexos e com idades entre 20 e 30 dias, provenientes do Setor de Zootecnia, do Departamento de Apoio, Produção e Saúde Animal, curso de Medicina Veterinária, Unesp, campus de Araçatuba. Para o exame histológico foram coletados fragmentos de diferentes segmentos (proximal, médio e distal) do trato gastrintestinal: esôfago, proventrículo, moela, intestino delgado (duodeno, jejuno e íleo) e intestino grosso (ceco, cólon e reto). O material foi fixado em solução de paraformaldeído a $4 \%$, processado e incluído em paraplast, com a finalidade de se proceder a microtomia. Os cortes histológicos adquiridos, com aproximadamente $5 \mu \mathrm{m}$ de espessura, foram posteriormente submetidos à coloração com Hematoxilina e Eosina e examinados ao microscópio de luz binocular Olympus CBA.

\section{Resultados}

Quanto à estrutura geral do trato gastrintestinal do avestruz, os órgãos que constituem o tubo digestório são: esôfago, proventrículo gástrico, ventrículo gástrico, intestino delgado e intestino grosso. A parede do tubo apresentou quatro camadas ou túnicas: mucosa, submucosa, muscular e serosa e/ou adventícia. As diferenças existem, principalmente na túnica mucosa, devido às características funcionais de cada segmento e serão descritas adiante. A mucosa apresentou epitélio com inúmeras glândulas mucosas, lâmina própria de tecido conjuntivo frouxo e muscular da mucosa de músculo liso. A submucosa composta por tecido conjuntivo denso ou frouxo, com glândulas, vasos sanguíneos e corpos celulares de neurônios formadores do plexo nervoso submucoso. A muscular era composta por duas camadas de fibras musculares lisas, a circular interna e a longitudinal externa separadas por vasos sanguíneos e corpos celulares de neurônios constituintes do plexo nervoso mioentérico. A serosa e/ou adventícia, camadas mais externas eram formadas por tecido conjuntivo frouxo e mesotélio, para a primeira, e tecido conjuntivo frouxo, para a segunda com vasos sanguíneos e tecido adiposo.

No esôfago, as regiões (proximal, média e distal) eram formadas por estruturas semelhantes. Contudo, as regiões média e distal apresentaram maior espessura em todas as camadas. Em corte transversal, observou-se luz com inúmeras pregas longitudinais por toda extensão, abrangendo a mucosa e submucosa, cujo revestimento era de epitélio estratificado pavimentoso não queratinizado, lâmina própria de tecido conjuntivo frouxo e numerosas glândulas tubuloacinosas de secreção mucosa com células secretoras cilíndricas cujos citoplasmas eram claros e os núcleos achatados na porção basal e a muscular da mucosa evidente. A submucosa era discreta, constituída de tecido conjuntivo frouxo, com inúmeros vasos sanguíneos. A camada muscular apresentou dois 
folhetos, o circular interno, espesso, e o longitudinal externo, mais delgado separados por áreas com vasos sanguíneos e corpos celulares de neurônios constituintes do plexo mioentérico. A adventícia e a serosa, esta última presente na parte distal, eram típicas, ou seja, a adventícia era formada por tecido conjuntivo frouxo e a serosa formada por tecido conjuntivo frouxo, revestida externamente por mesotélio (Figuras 1a e 1b).
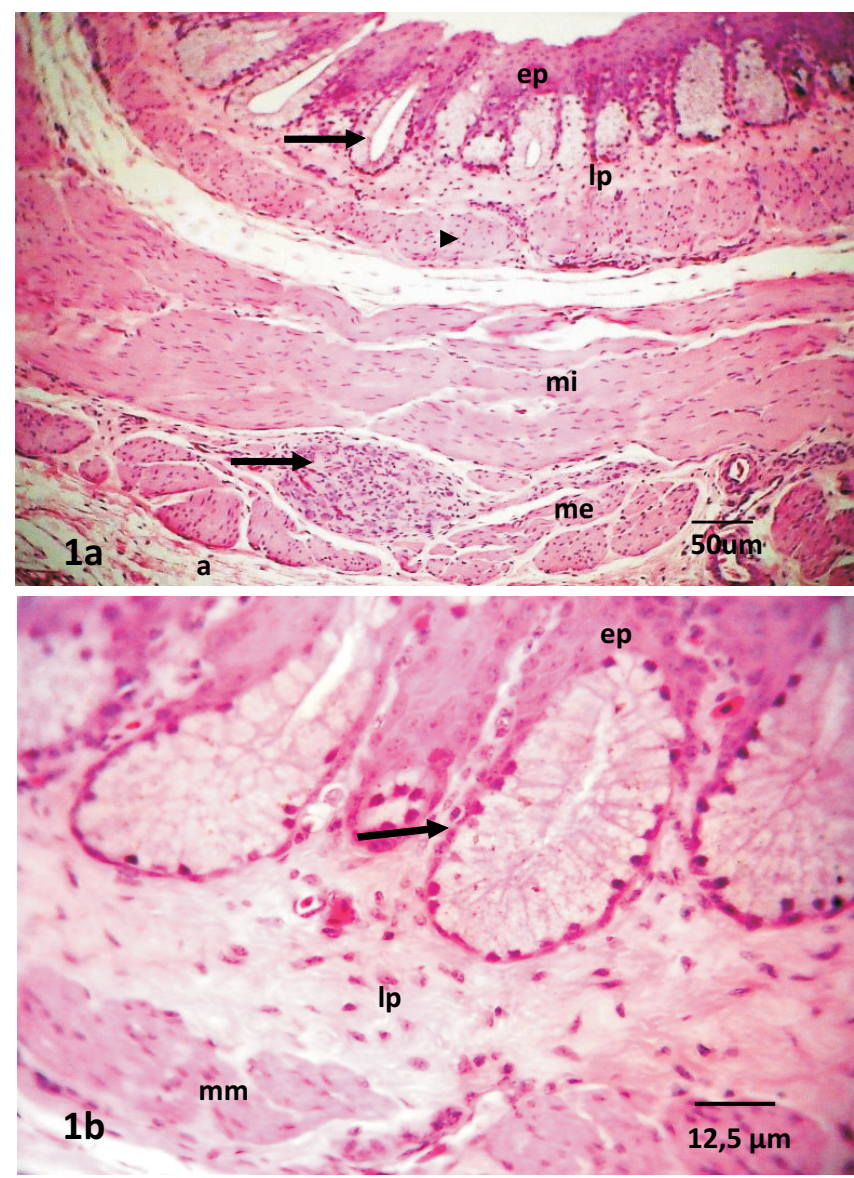

FIGURA 1: Fotomicrografia de esôfago de avestruz jovem. 1a Mucosa com epitélio estratificado pavimentoso (ep). Glândula mucosa (seta). Lâmina própria (lp). Muscular da mucosa (cabeça de seta). Submucosa (sm). Muscular interna (mi) e muscular externa (me). Plexo mioentérico (seta). Adventícia (a). Hematoxilina e eosina. Lente objetiva de 10x. 1b-Mucosa com epitélio estratificado pavimentoso (ep). Glândula mucosa (seta). Lâmina própria (lp). Muscular da mucosa (mm). Hematoxilina e eosina. Lente objetiva de 40x.

A mucosa do proventrículo gástrico apresentou numerosos pregueamentos, revestidos por epitélio simples cilíndrico, com presença de glândulas tubulares ramificadas revestidas por células cilíndricas de secreção mucosa com citoplasma claro e núcleo na porção basal, lâmina própria espessa, de tecido conjuntivo frouxo, e muscular da mucosa típica formada por fibras musculares lisas. A submucosa exibiu presença de numerosas glândulas tubuloalveolares em arranjos lobulares, compostas e ramificadas, com células acidófilas, que desembocam radialmente num grande ducto central revestido por epitélio pseudoestratificado. A túnica muscular apresentou duas subcamadas, a circular interna, espessa, e a longitudinal externa, mais delgada separadas por vasos sanguíneos e o plexo mioentérico. A serosa era formada por tecido conjuntivo frouxo e mesotélio (Figuras 2a e 2b).
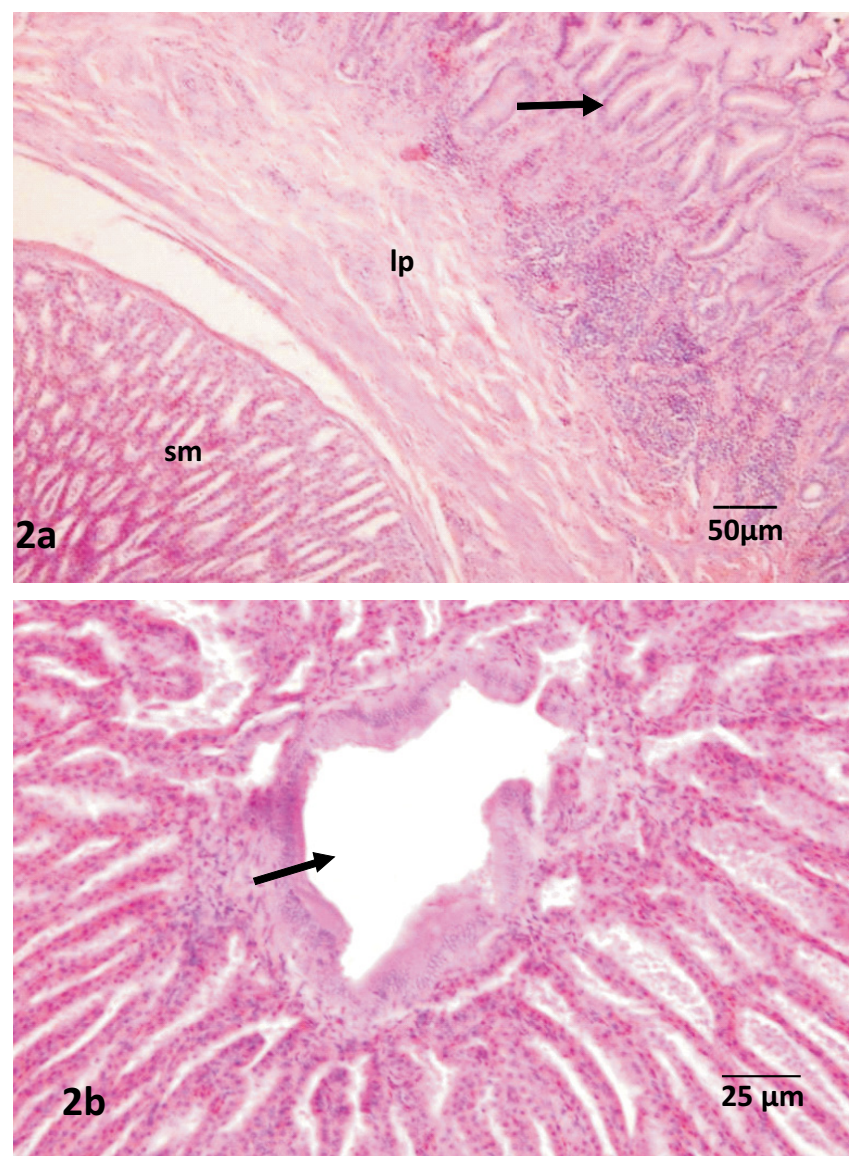

FIGURA 2: Fotomicrografia de proventrículo gástrico de avestruz jovem. 2a - Mucosa com glandulas (seta) e lâmina própria (lp). Glândula submucosa (sm). Hematoxilina e eosina. Lente objetiva de 10x. 2b - Glândula submucosa com ducto central (seta). Hematoxilina e eosina.

O ventrículo gástrico exibiu mucosa recoberta por uma camada espessa de substância rósea homogênea, logo abaixo um epitélio simples cilíndrico e lâmina própria de tecido conjuntivo frouxo, com glândulas tubulares simples ramificadas, mucosas, revestidas 
por epitélio simples cúbico, e muscular da mucosa não visível, assim como a submucosa. A túnica muscular era espessa, formada por músculo liso, em corte longitudinal, e tecido conjuntivo denso. A túnica serosa era típica formada por tecido conjuntivo frouxo e mesotélio (Figura 3).

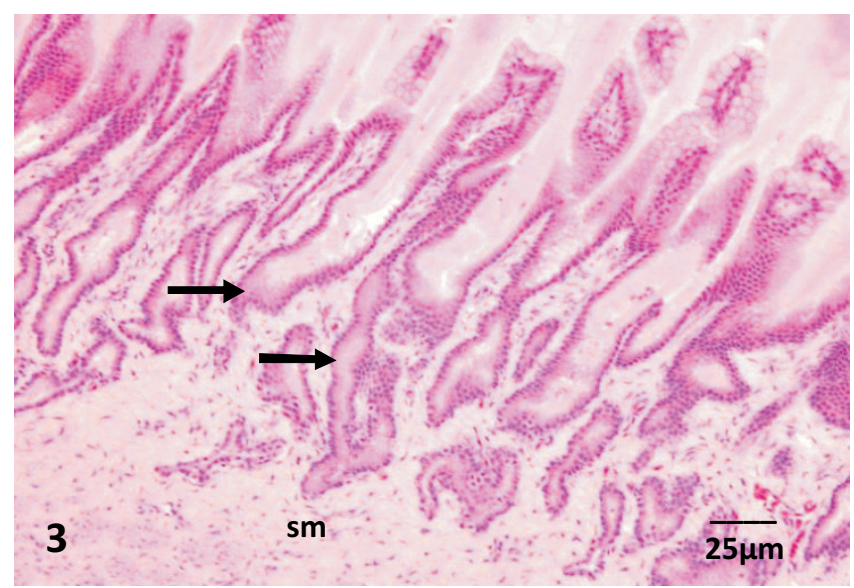

FIGURA 3: Fotomicrografia de ventrículo gástrico de avestruz jovem. Mucosa com glândulas tubulares (setas). Submucosa (sm). Hematoxilina e eosina.

No duodeno observou-se mucosa formada por longos vilos, revestidos por epitélio simples cilíndrico com células caliciformes e algumas células com núcleos grandes e claros, lâmina própria de tecido conjuntivo com glândulas tubulares e muscular da mucosa delgada. A submucosa era delgada, formada de tecido conjuntivo frouxo. A camada muscular exibiu dois estratos, o interno, circular e bem espesso, e o externo, longitudinal e delgado separados por gânglios nervosos mioentéricos. A serosa era formada de tecido conjuntivo frouxo e mesotélio externamente. As porções média e distal do duodeno apresentaram as camadas mais delgadas (Figura 4).

A porção média do íleo exibiu vilosidades menores e, na porção distal, curtas e largas, revestidas por epitélio simples cilíndrico com grande quantidade de células caliciformes, lâmina própria de tecido conjuntivo frouxo e muscular da mucosa delgada. A camada muscular e a serosa eram semelhantes às descritas para o duodeno $\mathrm{e}$ jejuno (Figura 5).

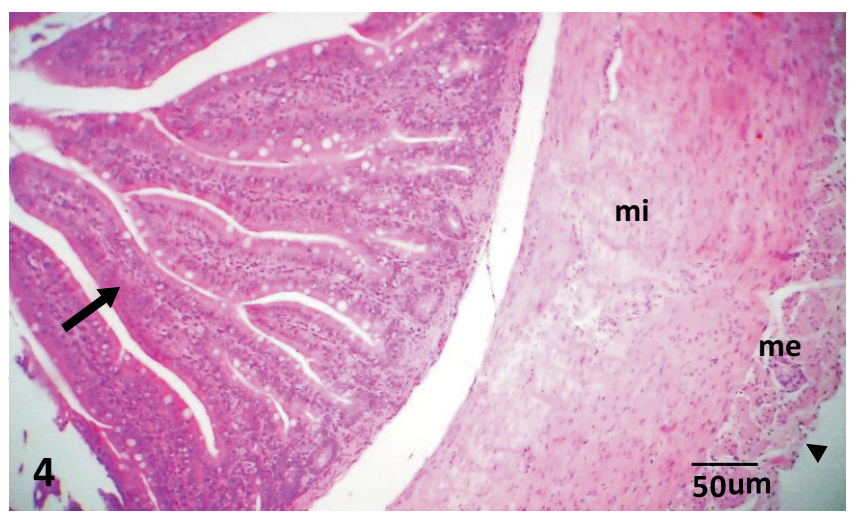

FIGURA 4: Fotomicrografia de corte de duodeno de avestruz jovem. Mucosa com vilos grandes (seta). Muscular interna (mi). Muscular externa (me). Serosa (cabeça de seta). Hematoxilina e eosina.

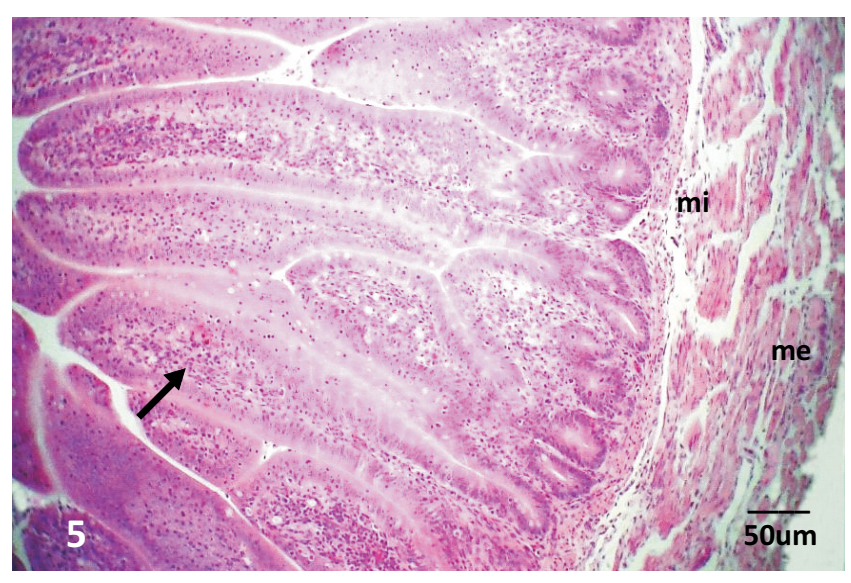

FIGURA 5: Fotomicrografia de corte de íleo de avestruz jovem. Mucosa com vilos pequenos (seta). Muscular interna (mi). Muscular externa (me). Hematoxilina e eosina.

No ceco, cólon e reto a mucosa era formada por pregas longitudinais revestidas por epitélio simples cilíndrico com glândulas tubulares formadas por epitélio cilíndrico com células caliciformes, lâmina própria de tecido conjuntivo, com leucócitos polimorfonucleares (neutrófilos) no reto, e muscular da mucosa delgada, em corte longitudinal. A submucosa era delgada e formada de tecido conjuntivo frouxo. A camada muscular era composta por duas camadas de fibras musculares lisas, a circular interna espessa e a longitudinal externa delgada e a serosa era formada por tecido conjuntivo frouxo e mesotélio (Figuras 6, 7 e 8). 


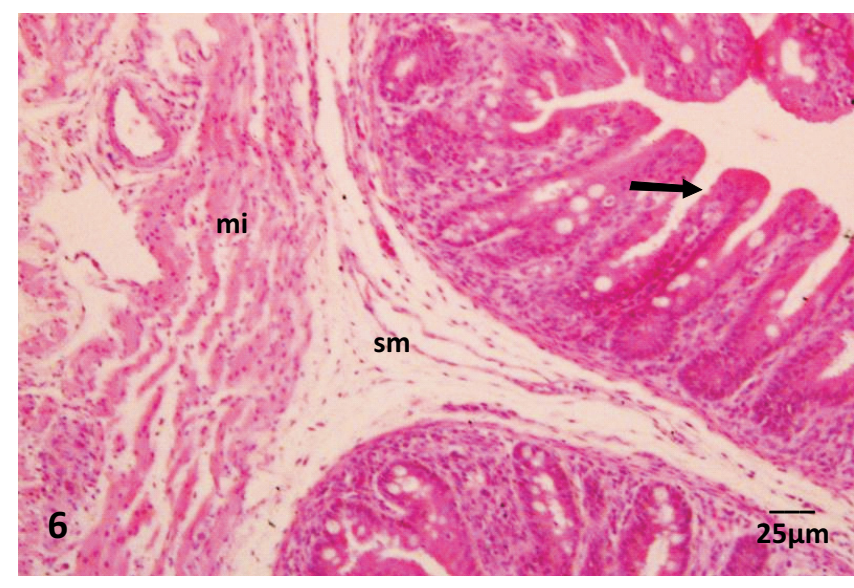

FIGURA 6: Fotomicrografia de corte de ceco de avestruz jovem. Mucosa com pequenos vilos (seta). Submucosa (sm). Muscular interna (mi). Hematoxilina e eosina.

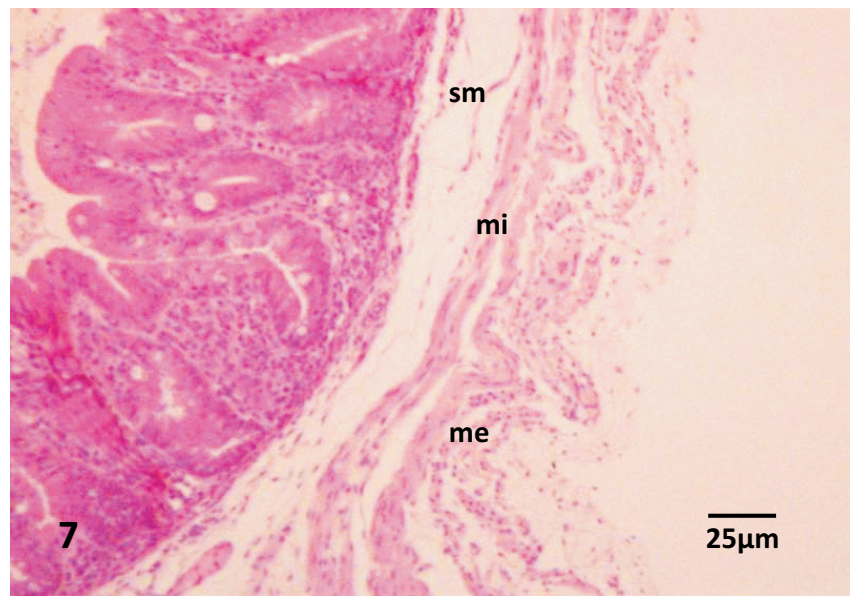

FIGURA 7: Fotomicrografia de corte de cólon de avestruz jovem. Mucosa com glândulas tubulares (seta). Submucosa (sm). Muscular interna (mi) e muscular externa (me). Serosa (cabeça de seta). Hematoxilina e eosina.

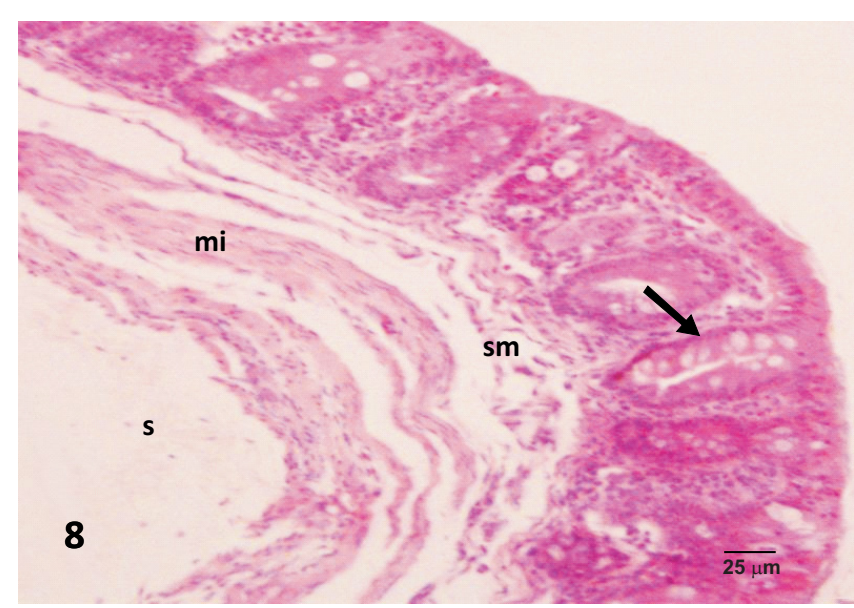

FIGURA 8: Fotomicrografia de corte de reto de avestruz jovem. Mucosa com glândulas tubulares (seta). Submucosa (sm). Muscular interna (mi). Serosa (s). Hematoxilina e eosina.

\section{Discussão}

Nossos resultados demonstraram que estas aves apresentam o tubo digestório com características anatômicas que permitem tanto a comparação com outras aves como com os ruminantes e outros herbívoros. Aliás, estas observações não se afastam daquelas assinaladas por Camiruaga e Simonetti (2003) como ausência de vesícula biliar e intestino grosso mais extenso que o intestino delgado. Um exemplo digno de nota é a ausência de inglúvio, cuja função passa a ser exercida pelo proventriculo gástrico e ventrículo gástrico (Angel, 1996; Camiruaga e Simonetti, 2003), cujas cavidades são quase simultâneas.

As dobras longitudinais encontradas na luz do esôfago formadas pela mucosa e submucosa, foram descritas por Illanes et al. (2006) para avestruzes adultos, assim como a mucosa revestida por epitélio estratificado não queratinizado. Ruminantes e eqüinos, por outro lado, apresentam respectivamente um grau de queratinização decrescente (Banks, 1992; Dellmann, 1993; Bacha e Bacha, 2003). Na lâmina própria havia numerosas glândulas tubuloacinosas simples, por toda a extensão do órgão, o que concorda com Illanes et al. (2006) que também verificaram as mesmas características em avestruzes adultos, porém afirmaram que essas glândulas são ramificadas. Estas observações quanto à quantidade dessas glândulas, são contrárias as de Banks (1992), Dellmann (1993) e Bacha e Bacha (2003), que relataram uma quantidade discreta dessas glândulas em ruminantes e eqüinos. A muscular da mucosa bem evidenciada corrobora as descrições de Illanes et al. (2006), pois torna claro que, esta é uma característica do avestruz jovem que se manteve até a fase adulta. A submucosa de tecido conjuntivo frouxo com vasos sanguíneos corresponde às descrições de Banks (1992), em aves domésticas. Em outras espécies de animais domésticos, segundo o autor, esta região ainda pode apresentar glândulas, ausentes em nossas observações.

As características do proventriculo gástrico aproximam-se às descritas em aves domésticas por Banks (1992), Dellmann (1993) e Bacha e Bacha (2003), e em avestruzes adultos por Bezuidenhout e Van Aswegen (1990) e Illanes et al. (2006). No entanto, algumas 
variações foram encontradas: as glândulas da submucosa desembocam radialmente num grande ducto central revestido por epitélio pseudoestratificado, diferindo de Bezuidenhout e Van Aswegen (1990) e Illanes et al. (2006), que o descreveram como simples cilíndrico, em avestruzes adultos. Banks (1993) e Bacha e Bacha (2003) afirmaram que este epitélio pode ser simples cilíndrico nas aves domésticas e Dellmann (1993), simples cúbico. Illanes et al. (2006) aludiram ainda à presença de uma camada espessa de tecido conjuntivo denso rodeando todo o órgão, característica ausente em avestruzes jovens, provavelmente devido a pouca idade dos animais, aliada ao pouco desenvolvimento do órgão. Por outro lado, Bezuidenhout e Van Aswegen (1990) não citaram tal estrutura em avestruzes adultos.

O ventrículo gástrico dos avestruzes jovens apresentava a superfície mucosa revestida por uma espessa camada de substância rósea e homogênea. Bezuidenhout e Van Aswegen (1990) descreveram em avestruzes adultos, presença de uma cutícula espessa produzida pelas glândulas ventriculares, cobrindo a mucosa. Já Illanes et al (2006) denominaram esta substância de aspecto córneo como cutícula ou glicocálix. Nesse aspecto, não foi possível afirmar a natureza dessa substância encontrada nos avestruzes jovens, mas que provavelmente seja córnea, pois esta é uma característica inerente ao órgão. Em aves domésticas, a ocorrência de um material queratinóide na mucosa do ventrículo gástrico, foi corroborada por Dellmann (1993), Bacha e Bacha (2003) e Samuelson (2007). Glândulas tubulares simples ramificadas estavam presentes na mucosa do ventrículo, cuja descrição morfológica corresponde a de Banks (1992) para aves domésticas, e a de Bezuidenhout e Van Aswegen (1990) para avestruzes adultos. Diferindo de nossas observações, Illanes et al (2006) descreveramnas como tubuloalveolares simples ramificadas. Não se pode visualizar a muscular da mucosa, provavelmente ainda não desenvolvida, devido a pouca idade dos animais ou por estar ausente em alguns locais, bem como fragmentada, como afirmaram Illanes et al. (2006) e Bezuidenhout e Van Aswegen (1990), respectivamente. A túnica muscular apresentava apenas uma camada espessa de músculo liso e tecido conjuntivo, semelhante às aves domésticas, segundo Banks (1992), Dellmann (1993), Bacha e Bacha (2003) e Samuelson (2007). Porém, em avestruzes adultos, Illanes et al. (2006) encontraram três camadas espessas e Bezuidenhout e Van Aswegen (1990) descreveram duas camadas, a interna espessa e a externa pouco desenvolvida ou incompleta em sua maior parte. Isto posto, podemos supor que tal característica ocorra durante o crescimento do animal, já que esta morfologia citada acima se refere aos animais adultos.

O duodeno, jejuno e íleo exibiram a camada muscular da mucosa delgada e em disposição longitudinal, diferindo de Bezuidenhout e Van Aswegen (1990), que a descreveram formada por duas camadas, a longitudinal e a circular, e de Illanes et al. (2006), que encontraram no duodeno e jejuno duas camadas, uma circular interna e uma longitudinal externa, e no íleo três camadas. Em aves domésticas, apenas uma camada longitudinal é descrita (Banks, 1992; Bacha e Bacha, 2003). No jejuno e íleo não foi observada submucosa, fato citado por Dellmann (1993), em aves domésticas. Estas variações talvez ocorram devido a fatores fisiológicos ou nutricionais, aliados às idades das aves, já que nossos achados correspondem a animais jovens, entre 20 e 30 dias.

A mucosa do ceco, cólon e reto mostraram dobras longitudinais, destituídas de vilosidades, com exceção do ceco, onde se observaram pequenos vilos, o que concorda com os resultados de Bezuidenhout e Van Aswegen (1990), que descreveram em avestruzes adultos a existência de pequenos vilos no ceco e reto, e Dellmann (1993), Bacha e Bacha (2003) e Samuelson (2007), que aludiram a presença dessas estruturas nas aves domésticas, com tendência a desaparecer em sua porção final. No entanto, Illanes et al. (2006) não descreveram as mesmas estruturas no ceco de avestruzes adultos. A muscular da mucosa era delgada, em corte longitudinal, diferindo de Illanes et al. (2006), que descreveram duas camadas na muscular da mucosa, uma circular interna e uma longitudinal externa; entretanto, Bezuidenhout e Van Aswegen (1990) acusaram a presença de ambas as subcamadas, porém inversas. Com base nos mesmos fatores descritos para as variações morfológicas que ocorreram no intestino delgado, podemos aferir o mesmo ao intestino grosso.

Com base nos resultados obtidos, podemos concluir que os diferentes segmentos do tubo digestório do avestruz jovem apresentam a mesma estrutura geral 
de outras aves e mamíferos domésticos, com algumas diferenças que podem ser decorrentes da idade, inerentes à espécie ou hábito alimentar. Tendo em vista que o avestruz é explorado zootecnicamente, diferentes tipos de ração poderão induzir às variações morfológicas no trato digestório o que poderá ser confirmado com a realização de experimentos abordando o tema. Esperamos que esta análise venha a contribuir para uma melhor compreensão dos processos fisiológicos relacionados à nutrição e ao manejo de avestruzes durante o seu crescimento.

\section{Referências}

Angel, C. R. 1996. A review of ratite nutrition. Animal Feed Science and Technology, 60: 241-246.

Bacha, W. J.; Bacha, L. M. 2003. Atlas colorido de histologia veterinária. $2^{\mathrm{a}}$ ed., Roca, São Paulo, Brasil, 457pp.

Banks, W. J. 1992. Histologia veterinária aplicada. $2^{\mathrm{a}}$ ed., Manole, São Paulo, Brasil, 629pp.

Bezuidenhout, A. J. 1986. The topography of the thoraco-abdominal viscera in the ostrich (Struthio camelus). Onderstepoort Journal of Veterinarian Research, 53 (2): 111-117.
Bezuidenhout, A. J.; Van Aswegwn, G. 1990. A light microscopic and immunocytochemical study of the gastrointestinal tract of the ostrich (Struthio camelus L.). Onderstepoort Journal of Veterinarian Research, 57: 37-48.

Camiruaga, M.; Simonetti, C. 2003. Avestruces, sistema digestivo y su alimentación. Revista Agronomía y Forestal UC, 12: 1014

Dellmann, H. D. 1993. Histologia veterinária. $2^{\mathrm{a}}$ ed., Acribia, Zaragoza, Espanha, 398pp.

Iji, P. A.; Van der Walt, J. G.; Brand, T. S.; Boomker, E. A.; Booyse, D. 2003. Development of the digestive tract in the ostrich (Struthio camelus). Archiv fur Tierernahrung, 57 (3): 217-228.

Illanes, J.; Fertilio, B.; Chamblas, M.; Leyton, V.; Verdugo, F. 2006. Descripción histológica de los diferentes segmentos del aparato digestivo de avestruz (Struthio camelus var. domesticus). International Journal of Morphology, 24: 205-214.

Marinho, M.; Meireles, M. V.; Souza, A. V. G. 2004. Determinação da microflora do trato gastrintestinal de avestruzes (Struthio camelus) criados na região noroeste do Estado de São Paulo, submetidas à necropsia. Arquivos do Instituto Biológico, 71: 267-271.

Samuelson, D. A. 2007. Tratado de histologia veterinária. Elsevier, Rio de Janeiro, Brasil, 527pp.

Santa Marta Avestruz. 2006. Carne de Avestruz. Disponível em $<$ http://www.avestruz.com.br/inicial/default.asp.>. Acesso em 18 de setembro de 2006. 